\title{
Evaluation and optimized selection of supersaturating drug delivery systems of posaconazole (BCS class 2b) in the gastrointestinal simulator (GIS): An in vitro-in silico-in vivo approach
}

\author{
Bart Hens ${ }^{\text {a, b, } 1}$, Marival Bermejo a, c, 1, Yasuhiro Tsume ${ }^{a}$, Isabel Gonzalez-Alvarez ${ }^{c}$, Hao Ruan ${ }^{\text {a }}$, Kazuki Matsui ${ }^{\text {a, d }}$, \\ Gregory E. Amidon ${ }^{\mathrm{a}}$, Katie Cavanagh ${ }^{\mathrm{a}}$, Gislaine Kuminek ${ }^{\mathrm{a}}$, Gail Benninghoffa, Jianghong Fan ${ }^{\mathrm{e}}$, \\ Naír Rodríguez-Hornedo ${ }^{\mathrm{a}}$, Gordon L. Amidon ${ }^{\mathrm{a}, *}$ \\ a Department of Pharmaceutical Sciences, College of Pharmacy, University of Michigan, Ann Arbor, MI 48109, USA \\ ${ }^{b}$ Department of Pharmaceutical and Pharmacological Sciences, KU Leuven, Herestraat 49, 3000 Leuven, Belgium \\ ${ }^{c}$ Department Engineering Pharmacy Section, Miguel Hernandez University, San Juan de Alicante, 03550 Alicante, Spain \\ d Pharmacokinetics Group, Biological Research Department, Sawai Pharmaceutical Co., Ltd., Osaka, Japan \\ e Office of Generic Drugs, Center for Drug Evaluation and Research, U.S. Food and Drug Administration, Silver Spring, MD, USA
}

\section{A R T I C L E I N F O}

Keywords:

Supersaturation

Precipitation

Supersaturating drug delivery systems

Differential scanning calorimetry

Microscopy

In vivo

In vitro

In silico

Oral bioavailability

Oral drug absorption

\begin{abstract}
A B S T R A C T
Supersaturating drug delivery systems (SDDS) have been put forward in the recent decades in order to circumvent the issue of low aqueous solubility. Prior to the start of clinical trials, these enabling formulations should be adequately explored in in vitro/in silico studies in order to understand their in vivo performance and to select the most appropriate and effective formulation in terms of oral bioavailability and therapeutic outcome. The purpose of this work was to evaluate the in vivo performance of four different oral formulations of posaconazole (categorized as a biopharmaceutics classification system (BCS) class $2 \mathrm{~b}$ compound) based on the in vitro concentrations in the gastrointestinal simulator (GIS), coupled with an in silico pharmacokinetic model to predict their systemic profiles. Recently published intraluminal and systemic concentrations of posaconazole for these formulations served as a reference to validate the in vitro and in silico results. Additionally, the morphology of the formed precipitate of posaconazole was visualized and characterized by optical microscopy studies and thermal analysis. This multidisciplinary work demonstrates an in vitro-in silico-in vivo approach that provides a scientific basis for screening SDDS by a user-friendly formulation predictive dissolution (fPD) device in order to rank these formulations towards their in vivo performance.
\end{abstract}

\section{Introduction}

It is estimated that $90 \%$ of the drug molecules in the discovery pipelines suffer from poor aqueous solubility (Loftsson and Brewster, 2010). Whether a poorly soluble molecule can become a therapeutic oral drug product is dependent on the ability to come up with a bioavailability-enhancing approach. 'Resolving' the issue of low aqueous solubility can be established by looking for an enabling formulation that will enhance drug dissolution in such way that supersaturated concentrations can be achieved, increasing the fraction of dissolved drug available for intestinal absorption (Brouwers et al., 2009;
Williams et al., 2013). Besides enabling formulations, supersaturation in the small intestine can also be created for basic drugs based on the $\mathrm{pH}$-shift from the stomach (i.e., high solubilizing environment) to the small intestine (i.e., low solubilizing environment) (Kostewicz et al., 2004). The concept of supersaturation as an effective oral bioavailability-enhancing approach has gained a lot of attention over the last decades. When consulting the ISI Web of Knowledge ${ }^{\circledR}$ database, mapping to the topics 'Supersaturation AND Precipitation AND Oral Absorption', the number of publications has been gaining momentum over the last decade as depicted in Fig. 1.

These enabling formulations that are responsible for creating supersaturated concentrations along the gastrointestinal (GI) tract are so-

\footnotetext{
* Corresponding author at: 428 Church St., College of Pharmacy, University of Michigan, Ann Arbor, MI 48109-1065, USA.

Email address: glamidon@med.umich.edu (G.L. Amidon)

1 Bart Hens \& Marival Bermejo should both be considered as a first author.
} 


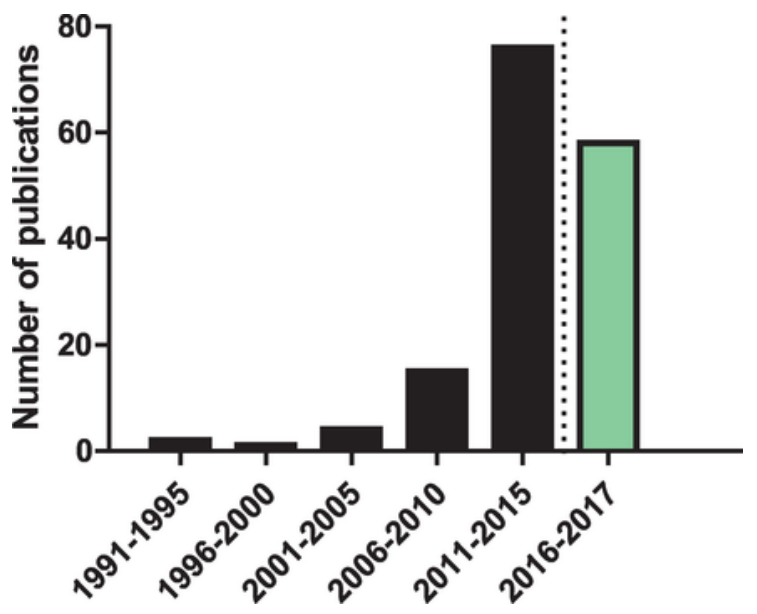

Fig. 1. Number of publications per five years in the ISI Web of Knowledge ${ }^{\circledR}$ database mapping to the topics 'Supersaturation' AND 'Precipitation' AND 'Oral Absorption' (last accessed on 10/02/2017). The green bar presents the number of publications gathered from 2016 until now. (For interpretation of the references to colour in this figure legend, the reader is referred to the web version of this article.)

called supersaturating drug delivery systems (SDDS) (Brewster et al., 2008; Gao and Shi, 2012; Laitinen et al., 2017). Throughout the years, a lot of in vitro research studies have been conducted in order to understand how these SDDS would actually behave in the human GI tract and exhibit their plasma profile after oral administration. A systematic and quantitative synopsis of the knowledge about SDDS has recently been published by Fong and colleagues (Fong et al., 2016). As an extensively and publicly debated topic, there are some important aspects that should be considered in order to gain valuable information about the biorelevant supersaturated concentrations and precipitated amounts of the administered drug (Bevernage et al., 2013; Lu et al., 2017; Sun et al., 2016; Sun and Lee, 2013). There are multiple in vitro models described in the literature that are frequently applied to evaluate supersaturation and precipitation for oral drug products; some of these models are more simple and static while other models are more complex and dynamic (Kostewicz et al., 2014b). Since supersaturation is a metastable state and the driving force for precipitation, an appropriate in vitro methodology to evaluate these phenomena is, needless to say, paramountly important for the efficient development and optimization of SDDS. For the last five years, several clinical aspiration studies have been performed in order to shed light on the in vivo performance of SDDS (Brouwers et al., 2017; Rubbens et al., 2016; Stappaerts et al., 2015). Using these data as a reference, multiple in vitro dissolution methodologies have been evaluated and optimized in order to improve their predictive power (Kourentas et al., 2016; Polster et al., 2010; Verwei et al., 2016). The gastrointestinal simulator (GIS) is one of these models that was successfully evaluated for forecasting the in vivo performance of different weakly basic compounds (BCS class $2 \mathrm{~b}$ drugs) that were tested in human aspiration studies (Matsui et al., 2015, 2016; Tsume et al., 2014, 2017a). The reason for its success is likely due to the biorelevance of how this model was built: GI variables (e.g., $\mathrm{pH}$, gastric emptying, secretions, transit times) are integrated into a physiologically-relevant manner in order to mimic and capture the in vivo performance of the oral drug product as good as possible.

Especially for enabling formulations (e.g., amorphous solid dispersions), GI variables such as gastric emptying and residual GI volumes are known to have a major impact on drug's behavior along the GI tract and thus are indispensable elements to be integrated into a formulation predictive dissolution (fPD) test (Hasler, 2008; Hens et al., 2016c; Mudie et al., 2014; Murray et al., 2017). Moreover, for delayed or controlled release drug products, a simple dissolution test may not be fully able to capture the in vivo performance of these oral drug prod- ucts. Formulation scientists would require more comprehensive information coming from a more dynamic, multi-compartmental in vitro device rather than a simple dissolution methodology. The generated in vitro dissolution profiles can be used as an input for in silico models in order to produce predicted plasma profiles which can directly be compared with the in vivo plasma profiles (Kostewicz et al., 2014a). This 'biopredictive dissolution' approach has emerged as a preferred option whenever pharmacokinetic data are available in order to validate the predictiveness of the in vitro model.

To this end, the purpose of this work was to evaluate the in vivo performance of four different oral formulations of posaconazole by performing dissolution studies in the GIS. The generated dissolution profiles served as an input for a computational pharmacokinetic model in order to simulate the systemic profiles of posaconazole. Intraluminal and systemic concentrations of posaconazole for the different formulations served as a reference to compare between in vitro and in vivo data, as recently published by Hens et al. (Hens et al., 2016a, 2016b). In addition, the morphology of formed precipitate of posaconazole was visualized and characterized by optical microscopy studies. This work demonstrates an in vitro-in silico-in vivo approach that gives us a rational framework and scientific basis for screening different oral drug products of the same drug compound by a user-friendly fPD device in order to select the most effective formulation for clinical studies in terms of oral bioavailability.

\section{Materials and methods}

\subsection{Chemicals}

Posaconazole and hydroxypropylmethylcellulose acetate succinate (HPMC-AS) was kindly donated by the Chemical Research Division of MSD (MSD Research laboratories, Merck Sharp \& Dohme Corp., Kenilworth, NJ, USA). Acetonitrile was obtained from VWR International (West Chester, PA). Methanol, $\mathrm{HCl}$ and trifluoroacetic acid (TFA) were purchased from Fisher Scientific (Pittsburgh, PA). $\mathrm{NaOH}, \mathrm{NaCl}$ and $\mathrm{NaH}_{2} \mathrm{PO}_{4} \cdot \mathrm{H}_{2} \mathrm{O}$ were received from Sigma-Aldrich (St. Louis, MO). Purified water (filtrated and deionized) was used for the analysis methods and dissolution studies to prepare the dissolution media (Millipore, Billerica, MA).

\subsection{Design of the in vitro dissolution studies performed with the GIS}

The GIS is a three-compartmental dissolution device, which con-

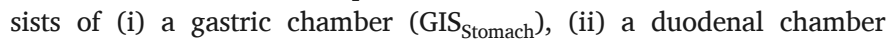
( GIS $_{\text {Duodenum }}$ ) and (iii) a jejunal chamber $\left(\right.$ GIS $_{\text {Jejunum }}$ ). The design of the GIS is depicted in Fig. 2 (Tsume et al., 2017b).

Four different formulations were tested in the GIS:

1. a solution of posaconazole (pH1.6; $20 \mathrm{mg}$ dissolved in $240 \mathrm{~mL}$ of tap water);

2. an acidified suspension of posaconazole ( $\mathrm{pH} 1.6$; $40 \mathrm{mg}$ dispersed in $240 \mathrm{~mL}$ of tap water);

3. a neutral suspension of posaconazole ( $\mathrm{pH} 7.1 ; 40 \mathrm{mg}$ dispersed in $240 \mathrm{~mL}$ of tap water);

4. a solid dispersion tablet of posaconazole $(100 \mathrm{mg}$ with $240 \mathrm{~mL}$ of tap water).

The manufacturing of both suspensions and solution were conducted by dispersing/dissolving Noxafil ${ }^{\circledR}$ suspension (Merck Sharp \& Dohme Corp., Kenilworth, NJ, USA) in $240 \mathrm{~mL}$ of tap water. The solid dispersion tablet (Merck Sharp \& Dohme Corp., Kenilworth, NJ, USA) was used as such without any manipulation. The formulations were poured into/added to the stomach compartment at the start of the 


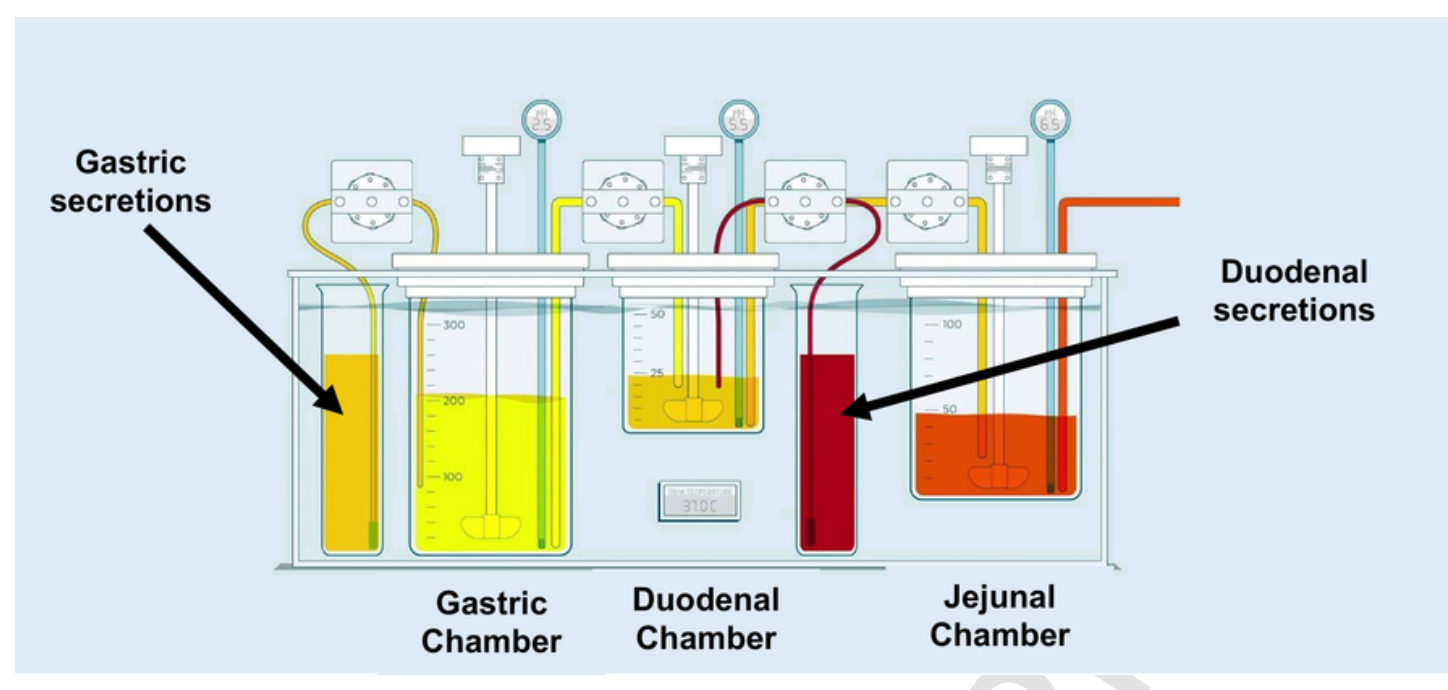

Fig. 2. Setup and design of the GIS that was applied to test the different formulations of posaconazole in fasted state conditions.

study. The dissolution media, initial volumes and secretion rates are described in Table 1.

Gastric emptying occurred by a first-order kinetic process with a gastric half-life of $13 \mathrm{~min}$, in line with the gastric half-life as measured in humans for liquids, ranging from 4 to $13 \mathrm{~min}$ (Hens et al., 2014). Duodenal volumes were kept constant during the entire experiment at a volume of $50 \mathrm{~mL}$. The jejunal compartment was left empty initially (i.e., no volume present). As soon as the experiment started, volumes of the GIS Stomach $_{\text {were transferred to the GIS }}$ Duodenum via a transfer tube by a peristaltic pump (Ismatec REGLO pump; IDEX Health and Science, Glattbrugg, Switzerland). Gastric and duodenal secretions $(1 \mathrm{~mL} / \mathrm{min})$ were ongoing during the entire experiment, coordinated by two peristaltic pumps. In order to keep the duodenal volume constant, duodenal content was transferred to the jejunal compartment $\left(\mathrm{GIS}_{\text {Jejunum }}\right.$ ). All peristaltic pumps were calibrated prior to the start of the experiment. The CM-1 overhead paddles (Muscle Corp., Osaka, Japan) stirred at a rate of 20 rotations per minute (RPM) in the gastric and duodenal chambers interspersed with a high-speed, quick burst every $25 \mathrm{~s}$ in order to mimic the more intensive contractions of stomach and duodenum; the weaker distal contractions of the intestinal tract were simulated in the jejunal chamber by stirring at a constant rate without any bursts. Two pH electrodes (Thermo Scientific, Orion 525A+, Waltham, MA) were placed in the gastric and duodenal chamber, respectively. All experiments were performed at $37^{\circ} \mathrm{C}$. After $60 \mathrm{~min}$, pumps were shut down as the gastric content was emptied. Concentrations in the duode-

Table 1

Fasted state experimental conditions in each compartment for testing the different drug formulations of posaconazole in the GIS.

\begin{tabular}{|c|c|c|c|}
\hline $\begin{array}{l}\text { Fasted } \\
\text { state test } \\
\text { conditions }\end{array}$ & $\mathrm{GIS}_{\text {Stomach }}$ & $\mathrm{GIS}_{\text {Duodenum }}$ & GIS $_{\text {Jejunum }}$ \\
\hline $\begin{array}{l}\text { Dissolution } \\
\text { media }\end{array}$ & $\begin{array}{l}\text { Simulated Gastric } \\
\text { Fluid (SGF), } \mathrm{pH} 2.0 \text {, } \\
0.01 \mathrm{M} \mathrm{HCl}\end{array}$ & $\begin{array}{l}\text { Simulated } \\
\text { Intestinal Fluid } \\
\text { (SIF), } \\
\text { pH7.5-100mM }\end{array}$ & / \\
\hline $\begin{array}{l}\text { Initial } \\
\text { volume }\end{array}$ & $\begin{array}{l}60 \mathrm{~mL} \text { SGF }+240 \mathrm{~mL} \\
\text { of tap water } \\
\text { (tablet)/liquid } \\
\text { formulation } \\
\text { (supensions/solution) }\end{array}$ & $50 \mathrm{~mL}$ & / \\
\hline Secretions & $1 \mathrm{~mL} / \mathrm{min}$ of $\mathrm{SGF}$ & $\begin{array}{l}1 \mathrm{~mL} / \mathrm{min} \text { of } \\
\text { SIF, } \\
\text { pH7.5-200 mM }\end{array}$ & / \\
\hline
\end{tabular}

num and jejunum were still measured up to $120 \mathrm{~min}$. Samples were withdrawn from the GIS compartments at predetermined time-points up to $120 \mathrm{~min}$ in order to measure (i) the dissolved amount of posaconazole, (ii) the total amount of posaconazole (i.e., solute and solid posaconazole) and (iii) thermodynamic solubility of posaconazole. The pumps, $\mathrm{pH}$ electrodes and overhead paddles were controlled by an in-house computer software program. Solution concentrations were determined by centrifuging $200 \mu \mathrm{L}$ of the withdrawn sample for $5 \mathrm{~min}$ at a speed of 17,000g (AccuSpin Micro 17, Fisher Scientific, Pittsburgh, PA). After centrifugation, the supernatant was directly two-fold diluted with methanol to capture the dissolved fraction. Total concentrations were determined by directly (i.e., no centrifugation step) diluting a withdrawn sample with methanol in order to capture dissolved and undissolved posaconazole. Finally, the thermodynamic solubility of posaconazole was determined by the shake-flask method (25 RPM), incubating the withdrawn samples for $24 \mathrm{~h}$ with an excess amount of posaconazole at $37^{\circ} \mathrm{C}$. All obtained samples were analyzed by HPLC (see below).

\subsection{Analysis of the mass transport of posaconazole throughout the GIS}

A mass transport analysis (MTA) was developed to describe the passage of dissolved posaconazole throughout all the chambers of the GIS. Mass transport equations for the GIS were constructed based on the drug dissolution, precipitation, and transit kinetics as earlier described for dipyridamole by Matsui and colleagues (Matsui et al., 2017). All these equations were adopted in order to describe the mass transport of posaconazole, with slight modifications specific to the physicochemical/biopharmaceutical parameters of posaconazole and corresponding formulations (Table 2). Mathematical equations are included in the supporting information.

Secretion rates in the gastric and duodenal chamber are given by $\mathrm{k}_{\mathrm{sec} \_\mathrm{s}}$ and $\mathrm{k}_{\mathrm{sec} \_\mathrm{d}}$, respectively; $\mathrm{t}_{1 / 2, \mathrm{G}}$ represents the gastric half-life of emptying; $V_{s}, \mathrm{~V}_{\mathrm{d}}$ and $\mathrm{V}_{\mathrm{j}}$ represent the gastric, duodenal and jejunal volumes. $\mathrm{Z}$ is a dissolution coefficient that is applied to both suspensions and the solution, considering the $\mathrm{pH}$-dependent dissolution and solubility of posaconazole. $\mathrm{Z}_{0_{0} s}$ represents a zero order dissolution coefficient to describe dissolution kinetics for the tablet in the GIS $S_{\text {Stomach. }} Z_{d}$ and $\mathrm{Z}_{\mathrm{j}}$ both represent dissolution rate constants for the tablet in the duodenal and jejunal chamber, respectively. Due to the delayed-release characteristics of the amorphous solid dispersion tablet, we came up with a description to simulate the controlled release of posaconazole in the intestinal tract, based on the amorphous properties of the formulated 
Table 2

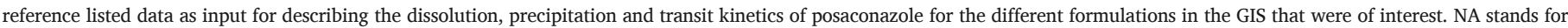
'Not Applicable'.

\begin{tabular}{|c|c|c|c|c|c|}
\hline & Solution & Acidic suspension & Neutral suspension & Tablet & Reference \\
\hline Dose (mg) & 20 & 40 & 40 & 100 & Hens et al., 2016a, 2016b \\
\hline Dose $(\mu \mathrm{mol})$ & 28.54 & 57.08 & 57.08 & 142.69 & Hens et al., 2016a, 2016b \\
\hline $\mathrm{k}_{\mathrm{sec} \_\mathrm{s}}(\mathrm{mL} / \mathrm{min})$ & 1 & 1 & 1 & 1 & Matsui et al., 2017 \\
\hline $\mathrm{k}_{\mathrm{sec} \_\mathrm{d}}(\mathrm{mL} / \mathrm{min})$ & 1 & 1 & 1 & 1 & Matsui et al., 2017 \\
\hline $\mathrm{t}_{1 / 2, \mathrm{G}}(\mathrm{min})$ & 13 & 13 & 13 & 13 & Hens et al., 2016a, 2016b \\
\hline$V_{s}(\mathrm{~mL})$ & 300 to 5 & 300 to 5 & 300 to 5 & 300 to 5 & Matsui et al., 2017 \\
\hline $\mathrm{V}_{\mathrm{d}}(\mathrm{mL})$ & 50 & 50 & 50 & 50 & Matsui et al., 2017 \\
\hline $\mathrm{V}_{\mathrm{j}}(\mathrm{mL})$ & 0 to 390 & 0 to 390 & 0 to 390 & 0 to 390 & Matsui et al., 2017 \\
\hline $\mathrm{Z}(\mathrm{mL} / \mu \mathrm{mol} / \mathrm{min})$ & $9.51 \mathrm{E}-11$ & 5.04E-09 & 7.44E-04 & NA & Optimized by fitting \\
\hline $\mathrm{Z}_{0 \_\mathrm{S}}(\mu \mathrm{mol} / \mathrm{min})$ & NA & NA & NA & 0.022 & Optimized by fitting \\
\hline $\mathrm{Z}_{\mathrm{d}}\left(\min ^{-\left(\mathrm{N}_{\mathrm{d}}-1\right)}\right)$ & NA & NA & NA & $5.41 \mathrm{E}-02$ & Optimized by fitting \\
\hline $\mathrm{N}_{\mathrm{d}}$ & NA & NA & NA & 0.2 & Optimized by fitting \\
\hline $\mathrm{Z}_{\mathrm{j}}\left(\min ^{-\left(\mathrm{N}_{\mathrm{j}}-1\right)}\right)$ & NA & NA & NA & 3.61E-04 & Optimized by fitting \\
\hline $\mathrm{N}_{\mathrm{j}}$ & NA & NA & NA & 0.88 & Optimized by fitting \\
\hline $\mathrm{k}_{\text {pre_d }}\left(\min ^{-1}\right)$ & 8.75 & 8.98 & 1.08 & 1.83 & Optimized by fitting \\
\hline $\mathrm{k}_{\text {prej }}\left(\min ^{-1}\right)$ & $6.65 \mathrm{E}-3$ & 1.53 & 5.69 & 0.11 & Optimized by fitting \\
\hline
\end{tabular}

compound. This model was based on the Korsmeyer-Peppas model to simulate the controlled-release of posaconazole in the intestinal segments, independent of $\mathrm{pH}$. Korsmeyer et al. derived a simple relationship which described controlled drug release by a controlled dissolution rate (dictated by a dissolution rate constant Z) (Peppas, 1985). Modifications to this equation were applied in order to simulate controlled release of posaconazole from the solid dispersion tablet as used in our study (Eq. 1):

$\frac{d M_{t}}{d t}=Z \cdot M_{\text {solid_t } t} \cdot t^{N}$

where $\frac{d M_{t}}{d t}$ is the fraction of drug released at time $t$ whereas $\mathrm{Z}$ is the dissolution rate constant, $M_{\text {solid_t }}$ is the solid amount of drug at time ' $t$ ' and $\mathrm{N}$ is the release exponent. The $\mathrm{N}$ value is used to characterize different release mechanisms for cylindrically-shaped matrices. The release exponents $N_{d}$ and $N_{j}$ were applied to simulate the release kinetics going on in the intestinal segments of the GIS. Precipitation rate constants are described as first-order kinetic process listed by $\mathrm{k}_{\text {pre_d }}$ and $\mathrm{k}_{\text {prej. }}$.

\subsection{In silico simulations to predict the systemic pharmacokinetic (PK) profiles of posaconazole}

A two-compartmental PK model was built in order to predict the plasma profiles after administration of both suspensions and the tablet. This model represents a systemic and peripheral compartment. Fitting and simulations were performed with Phoenix WinNonlin version 7.0 licensed to the University of Michigan. The design of the model is analog to the model as described by Matsui et al. with slight modifications to PK parameters (Fig. 3) (Matsui et al., 2017).

Critical model PK parameter estimates to were extracted from intravenous (i.v.) data (50 mg single-dose i.v. administration to 9 healthy volunteers), such as the distribution/elimination rate constants in order to simulate distribution and elimination of the drug appropriately (Kersemaekers et al., 2015). The effective permeability $\left(P_{\text {eff }}\right)$ value was obtained from a recently published paper (Hens et al., 2017a). Simulated profiles were directly compared with the mean in vivo plasma profiles $(n=5)$ obtained from previous clinical studies. The PK parameters are listed in Table 3.

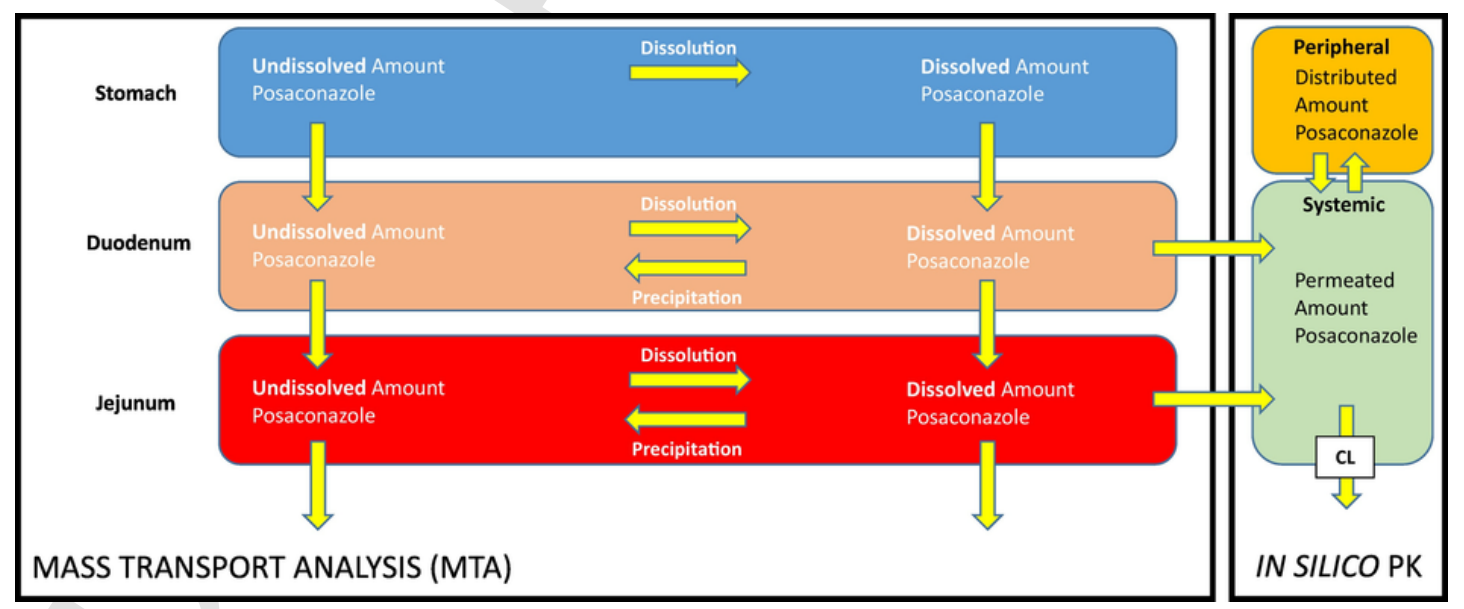

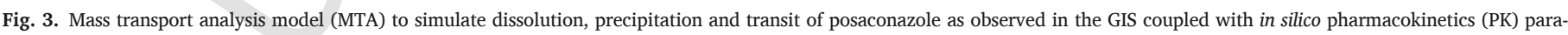
meters in order to simulate plasma profiles of both suspensions and the tablet. 
Table 3

Systemic PK parameters applied for in silico modeling of posaconazole in order to predict the simulated plasma profiles of both suspensions and the tablet.

\begin{tabular}{|c|c|c|}
\hline Pharmacokinetic (PK) parameters & Value & References \\
\hline Central compartment volumen $-V_{\mathrm{c}}(\mathrm{L})$ & 61.15 & $\begin{array}{l}\text { Kersemaekers et } \\
\text { al., } 2015\end{array}$ \\
\hline $\begin{array}{l}\text { Elimination rate constant from central } \\
\text { compartment }-k_{\mathrm{e}}\left(\mathrm{h}^{-1}\right)\end{array}$ & 0.17 & $\begin{array}{l}\text { Kersemaekers et } \\
\text { al., } 2015\end{array}$ \\
\hline $\begin{array}{l}\text { Distribution rate constant from central to } \\
\text { peripheral compartment }-k_{12}\left(\mathrm{~h}^{-1}\right)\end{array}$ & 3.14 & $\begin{array}{l}\text { Kersemaekers et } \\
\text { al., } 2015\end{array}$ \\
\hline $\begin{array}{l}\text { Distribution rate constant from peripheral } \\
\text { to central compartment }-k_{21}\left(\mathrm{~h}^{-1}\right)\end{array}$ & 1.10 & $\begin{array}{l}\text { Kersemaekers et } \\
\text { al., } 2015\end{array}$ \\
\hline Clearance - $C L(\mathrm{~L} / \mathrm{h})$ & 10.5 & $\begin{array}{l}\text { Kersemaekers et } \\
\text { al., } 2015\end{array}$ \\
\hline $\begin{array}{l}\text { Effective permeability small intestine }-P_{\text {eff }} \\
(\mathrm{cm} / \mathrm{h})\end{array}$ & 2.31 & Hens et al., 2017a \\
\hline
\end{tabular}

\subsection{Optical microscopy to study the morphology and time to the appearance of the precipitation of posaconazole.}

To visualize the appearance and morphology of the precipitation behavior of posaconazole in different test conditions, optical microscopy studies were conducted to gain information about the appearance of the initial dispersed particles and the formed precipitate (Lipert and Rodríguez-Hornedo, 2015). All microscopy studies were conducted at room temperature $\left(22-23^{\circ} \mathrm{C}\right)$ using an inverted optical microscope (Nikon, Diaphot-TMD, Melville, NY) with $20 \times$ and $40 \times$ Nomarski objectives. Transfer experiments were performed in a 96-well plate by adding $150 \mu \mathrm{L}$ of liquid formulation (solution or suspensions) directly into $150 \mu \mathrm{L}$ of $200 \mathrm{mM}$ phosphate buffer (pH7.5), mimicking the GIS experimental conditions. Pictures were taken at predetermined time points ( $0 \mathrm{~min}, 15 \mathrm{~min}, 30 \mathrm{~min}$ and $24 \mathrm{~h}$ ) to visualize precipitation. To explore the precipitation-inhibiting effects of HPMC-AS on supersaturated concentrations, $0.05 \%(w / v)$ of the polymer was added to $200 \mathrm{mM}$ of phosphate buffer (pH7.5). After a 1:1 dilution with a $10 \mathrm{mg}$ solution of posaconazole ( $\mathrm{pH} 1.6$ ), the time to induction of precipitation was checked and compared to the same conditions but without HPMC-AS. Solid-state characteristics were evaluated by using polarized optical microscopy (POM) (Leica, DMPL, Bannockburn, IL). A full wave plate filter was used in conjunction with crossed polarizers to enhance the optical features of some of the samples for image collection. Images were collected with a Spot Insight FireWire 4 Megasample Colour Mosaic camera controlled with Spot software (Sterling Heights, MI).

\subsection{Thermal analysis of precipitate}

Due to the extensive precipitation that was observed during dissolution studies in the GIS, a differential scanning calorimetry (DSC) study was performed in order to reveal the solid state of the precipitate. A $250 \mathrm{mg}$ solution was prepared in $250 \mathrm{~mL}$ of water at $\mathrm{pH} 1$. Precipitation of posaconazole was formed/induced by shifting the $\mathrm{pH}$ from 1 to 7.8 (titration with $1 \mathrm{M}$ of $\mathrm{NaOH}$ ). The precipitate was separated from the liquid media by filtration and dried at room temperature prior to DSC analysis. For comparison purpose, pure posaconazole powder was analyzed by DSC as a control. DSC was performed using a DSC 2910 modulated DSC instrument (TA Instruments, New Castle, DE) with a refrigerated cooling system (RCS) attached. DSC experiments were performed by heating the samples at a rate of $10^{\circ} \mathrm{C} / \mathrm{min}$ under a dry nitrogen atmosphere. A high purity indium standard was used for temperature and enthalpy calibration. Standard aluminum sample pans were used for all measurements, crimped with a pinhole lid.

\subsection{Analysis of posaconazole by HPLC}

All samples derived from the GIS studies were analyzed for posaconazole by HPLC-UV (Hewlett Packard series 1100 HPLC Pump combined with Agilent Technologies 1200 Series Autosampler). A volume of $100 \mu \mathrm{L}$ was injected into the HPLC system connected to a UV-lamp that was able to detect posaconazole at a wavelength of $254 \mathrm{~nm}$ (Agilent 1100 Series UV lamp). A gradient run with a mixture of acetonitrile and purified water (both containing $0.1 \%$ TFA) was used to detect posaconazole at a retention time of $8.9 \mathrm{~min}$ using a C-18 column (Kinetex C18 HPLC column, $250 \times 4.60 \mathrm{~mm}-5 \mu \mathrm{m}$, Phenomenex, Golden, CO) and a $1 \mathrm{~mL} / \mathrm{min}$ flow rate. Calibration curves were made in mobile phase based on a stock solution of posaconazole in methanol $(7 \mathrm{mM})$. Linearity was observed between $50 \mu \mathrm{M}$ and $39 \mathrm{nM}$. The observed peaks were integrated using ChemStation software (Agilent Technologies). The developed analytical method met the FDA requirements for bioanalytical method validation (Food and Drug Administration, 2001).

\subsection{Data analysis \& presentation}

Dissolution profiles of posaconazole derived from the GIS were plotted as a function of time and were expressed as the observed degree of supersaturation (DS) and the fraction of precipitated posaconazole $(\pi$; in case of a solution) or the fraction of solid amount of posaconazole ( $X$; in case of the suspensions or tablet). The same data analysis was conducted for the in vivo studies. The DS was expressed as:

$D S=\frac{\mathrm{C}}{C_{e q}}$

where $\mathrm{C}$ is the dissolved concentration of posaconazole at a specific time point and $C_{e q}$ is the thermodynamic solubility of posaconazole at that same time point. In order to express $\pi$ or $X$, the following equations were applied:

$\pi=1-\frac{C}{C_{t}}$

$\underline{Q}=1-\frac{C}{C_{t}}$

where $C$ is the dissolved concentration of posaconazole at a specific time point and $C_{t}$ is the total concentration (i.e., solute and precipitated posaconazole) at that same time point. The same equation can be used to calculate the fraction of solid amount of posaconazole in case of the suspensions/tablet. Notice that, in this case, $C_{t}$ represents solute, precipitated and initial solid particles of posaconazole. Amounts of posaconazole (dissolved and total) were plotted as a function of time throughout the different chambers of the GIS and presented as mean $\pm \operatorname{SD}(n=3)$.

\section{Results and discussion}

\subsection{Formulation performance of the posaconazole formulations in the GIS}

Fig. 4 depicts the amounts of posaconazole plotted as a function time for the four different formulations, showing dissolved amounts, total amounts and thermodynamic solubility of posaconazole for all experimental conditions. The dotted line represents the MTA that was simulated by the mathematical equations. The last column presents the 


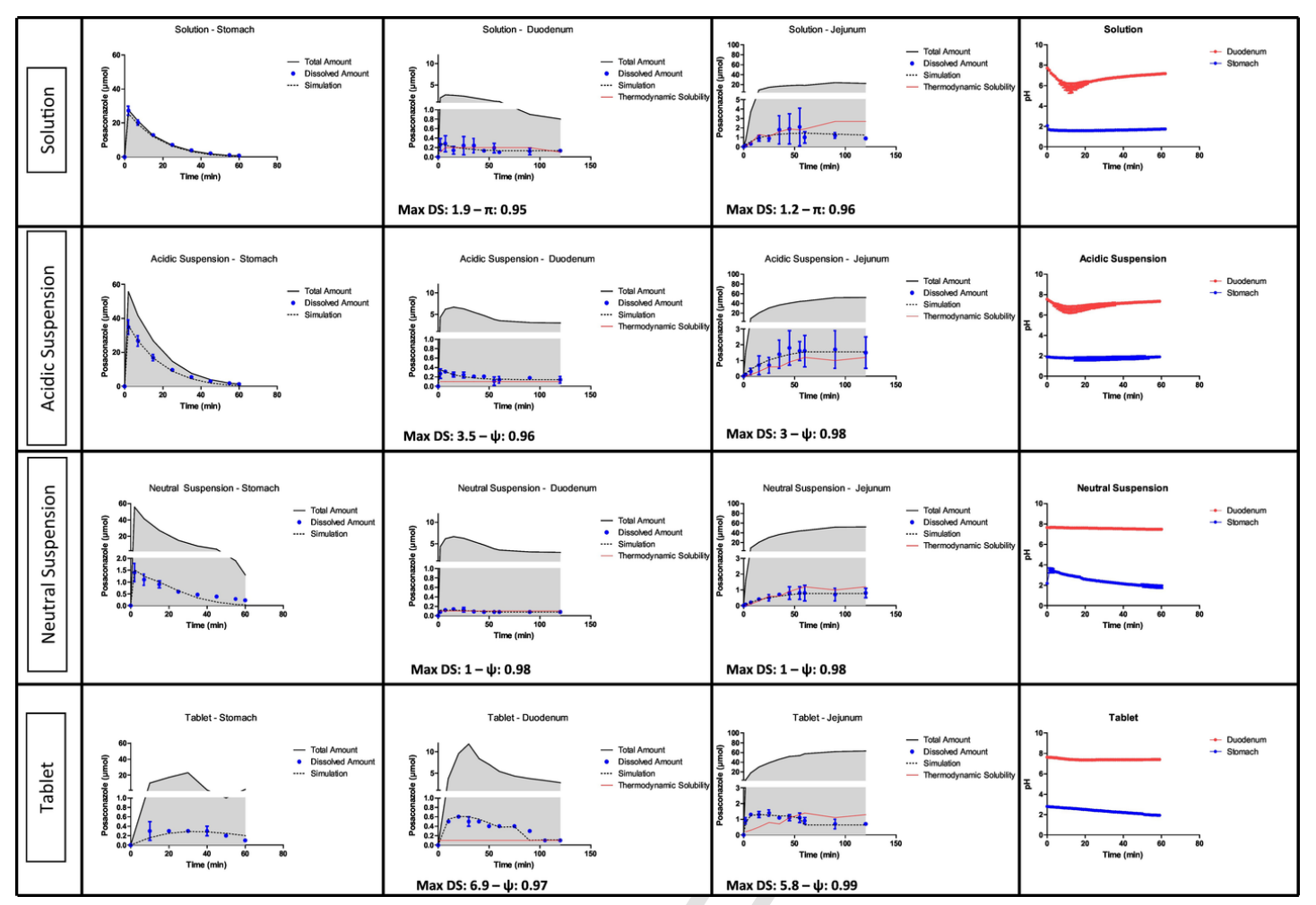

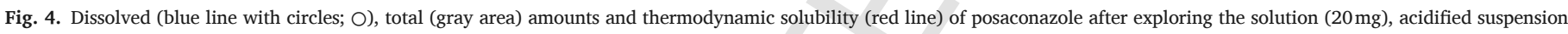

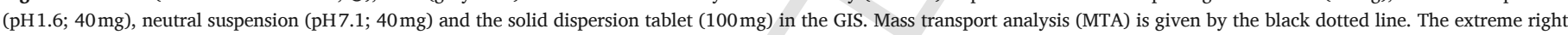

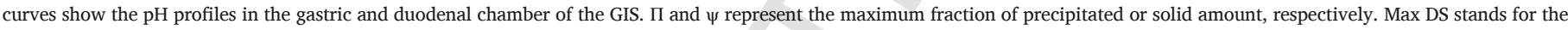

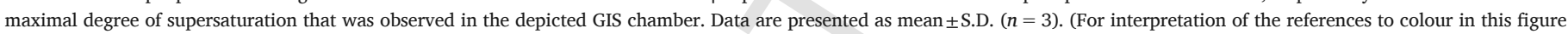
legend, the reader is referred to the web version of this article.)

$\mathrm{pH}$ values measured in the gastric and duodenal chamber as a function of time.

\section{- Posaconazole solution (20 mg; pH 1.6)}

Total and dissolved amounts of posaconazole overlapped in the gastric chamber of the GIS, indicating that no gastric precipitation of posaconazole was observed before entering the duodenal chamber. Upon entry in the duodenal chamber, precipitation was extensively pronounced with a maximum precipitated fraction of $95 \%$ at $15 \mathrm{~min}$, very close to the $92 \%$ of maximum precipitation observed in the duodenum after intragastric administration of the solution to healthy volunteers (Hens et al., 2016a). Upon entry in the duodenal chamber, a theoretical degree of supersaturation (DS) of 25 would be expected directly after gastric emptying. The onset of precipitation is immediate, though, resulting in a maximum DS of 1.9, which is in line with the one observed in vivo (DS 2.9). However, it should be noted that the maximum DS observed in vivo was highly variable from person to person (DS $2.9 \pm 14$ ). In vivo as well as in vitro (GIS), the time period of observed supersaturated concentrations was minimal (approximately $7 \mathrm{~min}$ ). Since no solid particles ('seeds') of posaconazole were present in the stomach that could facilitate precipitation, it can be stated that posaconazole easily crashes out; this phenomenon has not been observed for two other bases, dipyridamole and ketoconazole. For these two compounds, precipitation was limited and supersaturation was observed up to $50 \mathrm{~min}$. One of the challenges in this experiment was to keep the $\mathrm{pH}$ above the pKa's of posaconazole (3.6 and 4.6) in order to capture precipitation. With a minimal duodenal $\mathrm{pH}$ of 5.76 on average, this goal was achieved. In contrast, the duodenal $\mathrm{pH}$ observed in vivo was quite low and variable (ranging from $\mathrm{pH} 2$ to $\mathrm{pH} 5$ ) for the first aspirated samples up to $7 \mathrm{~min}$. This observed lower $\mathrm{pH}$ can be highly ex- plained by (i) a high volume of acidic solution that entered the duodenum (based on total concentrations) because of the fast gastric emptying for liquids in fasted state (Hens et al., 2014) and (ii) the low buffer capacity of duodenal fluids to sufficiently buffer the incoming gastric solution and residual gastric fluids (Hens et al., 2017b). No supersaturated concentrations were observed in the GIS $_{\text {Jejunum, likely due to the high }}$ amount of precipitation occurring directly in the duodenum. However, this prediction cannot be confirmed by in vivo data as no jejunal samples were taken during the human aspiration study.

\section{- Posaconazole acidic suspension (40 mg; pH 1.6)}

In line with what was observed in the human stomach, incomplete gastric dissolution was also observed after pouring the acidic suspension

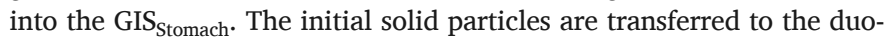
denal chamber where they can serve as nuclei to initiate crystal growth, enhancing the precipitation of posaconazole (Rodríguez-Hornedo and Murphy, 1999). As observed in vivo and in vitro, posaconazole precipitated rapidly upon entry the duodenum with a maximum DS of 3.2 and 3.5, respectively. Mean maximum percentage of the solid amount (i.e., the sum of precipitated posaconazole and initial solid particles) that was observed in vivo and in vitro in the duodenum was $85 \%$ versus $96 \%$, respectively. The fraction of solid amount was even higher in the GIS $_{\text {Jejunum }}(98 \%)$, but cannot be compared and validated due to the lack of in vivo data. It was hypothesized that precipitation may be overestimated/overpredicted in in vitro/in silico models when the ability for the drug to be absorbed is neglected (Bevernage et al., 2012; Carlert et al., 2010, 2012; Shi et al., 2016; Tsume et al., 2017a). Taking this physiological-relevant barrier into consideration, future work is now focusing on the implementation of an absorptive sink into the GIS that mimics precisely the permeability 
of the intestinal membrane in order to have a biorelevant reflection of intestinal absorption of drug compounds. Besides permeability, solubility is also known as a predictor for oral absorption (Augustijns et al., 2014). The systemic outcome of the oral suspension is favorite when the suspension will be taken in presence of a liquid meal. It has been shown that the solubility of posaconazole in human fed state intestinal fluids is higher than in fasted state intestinal fluids (Hens et al., 2016b). Administration of posaconazole in presence of a liquid meal, will enhance the solubility of posaconazole and thus create an increased driving force for intestinal absorption (Sansone-Parsons et al., 2006). The difference in solubility of posaconazole between fasted and fed state human intestinal fluid is $5.1( \pm 0.2)$ and $53.9( \pm 18.8) \mu \mathrm{M}$, respectively (Augustijns et al., 2014). Consequently, based on eq. 2 , this will result in a lower degree of supersaturation (Eq. (2)) compared to the fasted state conditions. As the GIS is compatible to work with a liquid meal (e.g., Pulmocare $\left.{ }^{\circledR}\right)$, future studies can be put forward to focus on food-drug product interactions.

- Posaconazole neutral suspension (40 mg; pH7.1)

The amount of dissolved posaconazole in the GIS Stomach $_{\text {was lower }}$ for the neutral suspension than for the acidic suspension due to the $\mathrm{pH}$, as seen in Fig. 3 (last column). If the drug is less dissolved, solid drug particles are more present which may trigger precipitation of posaconazole immediately upon entry in the small intestine: this was clearly seen in vivo and also reflected in the GIS. No supersaturated concentrations were observed in the GIS $_{\text {duodenum }}$ and GIS $_{\text {jejunum }}$ as thermodynamic solubility was equal to the amount observed. The percentage of the solid amount that was observed in vivo ranged from $93 \%$ to $99 \%$ after administration of the neutral suspension. The maximum fraction of solid amount seen in vitro was $98 \%$ and thus in line with the in vivo data.

\section{- Posaconazole solid dispersion tablet (100 mg)}

Based on the in vivo and in vitro findings regarding the solution and suspensions, we can clearly state that fasted state posaconazole absorption appeared limited and variable, depending strongly on (i) gastric $\mathrm{pH}$ and extent of gastric dissolution, and (ii) duodenal precipitation following the transfer from the stomach into the small intestine. Regardless of formulation tested (i.e., suspensions versus solution), precipitation is extremely fast, confirming that the extent of dissolution in the stomach is a crucial process determining the systemic exposure of posaconazole. To cater to these sources of intersubject variability in terms of plasma $\mathrm{C}_{\max }$ and AUC, formulation scientists came up with a novel delayed-release solid dispersion tablet. This tablet was manufactured by dispersing amorphous posaconazole by hot-melt extrusion in a $\mathrm{pH}$-sensitive polymer matrix consisting of HPMC-AS (pKa 5.5). In that way, problems like (i) altered gastric $\mathrm{pH}$ in patients can be solved by working with HPMC-AS as a gastro-resistant polymer and (ii) intensive intestinal precipitation will be minimized by using this polymer as a precipitation/recrystallization inhibitor in the intestinal tract (Jackson et al., 2014; Patel and Anderson, 2014; Xu and Dai, 2013). The release of posaconazole was minimal in the GIS $_{\text {Stomach }}$ as well as in the human stomach, demonstrating the gastro-resistant properties of the polymer. Whenever being transferred to the duodenal chamber, posaconazole generated low yet metastable supersaturated concentrations (Augustijns and Brewster, 2012). Upon entry into the GIS $_{\text {jejunum }}$, supersaturation was even more pronounced. The controlled release of posaconazole seems to be time-dependent and more pronounced in the distal regions of the GI tract when comparing total concentrations between GIS $_{\text {Duodenum }}$ and GIS $_{\text {Jejunum. }}$ This was also observed in vivo, where the release of posaconazole was favored more downwards the GI tract (Hens et al., 2016b). It was hypothesized by the authors that the duodenum (with a length of approximately $25 \mathrm{~cm}$ ) is not the critical site to fully explore the mechanisms of action of this formulation. The gradual release and the presence of a precipitation inhibitor can explain this mechanism of sustained supersaturation in the jejunum. The maximum DS observed in humans

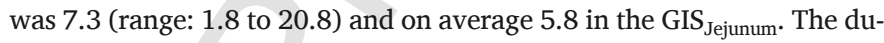
ration of supersaturation was on average $93 \mathrm{~min}$ (range: 30 to $205 \mathrm{~min}$ ) in vivo and $60 \mathrm{~min}$ in vitro. In order to find out the impact of supersaturation on systemic availability, an in silico PK model was built to simulate plasma concentrations of posaconazole for both suspensions and the tablet (the solution was excluded due to the lack of PK data).

3.2. In silico PK model to forecast the systemic performance of oral formulations

Plasma profiles of the acidic suspension, neutral suspension and tablet were simulated by a two-compartmental in silico PK model. The predicted outcome is illustrated in Fig. 5.

The plasma drug concentration-time profile after oral administration of $40 \mathrm{mg}$ acidic suspension, $40 \mathrm{mg}$ neutral suspension and $100 \mathrm{mg}$ solid dispersion were predicted using the mass transport equations as depicted in the supporting information. Drug absorption was simulated based on the effective permeability that was derived from Caco- 2 experiments (Hens et al., 2017a). Systemic concentrations are dependent on (i) the drug distribution between the peripheral and systemic compartment (controlled by distribution rate constants; $k_{12}$ and $k_{21}$ ) and (ii) the ongoing clearance (controlled by the elimination rate constant; $k_{\mathrm{e}}$ ). A previous in silico physiologically-based pharmacokinetic (PBPK) model that was applied to simulate the GI and systemic behavior of the acidic and neutral suspension observed that $99 \%$ of the $40 \mathrm{mg}$ dose was absorbed from the gut (Hens et al., 2017a). Since a majority of the posaconazole was still undissolved in the GIS, a scaling factor was applied to correct for the observed fraction absorbed $\left(\mathrm{F}_{\mathrm{a}}\right)$. This scaling factor accounts for the difference in magnitude or time scale between the in vitro dissolution profile and the in vivo luminal dissolution. According to FDA guidelines to demonstrate an in vitro-in vivo correlation
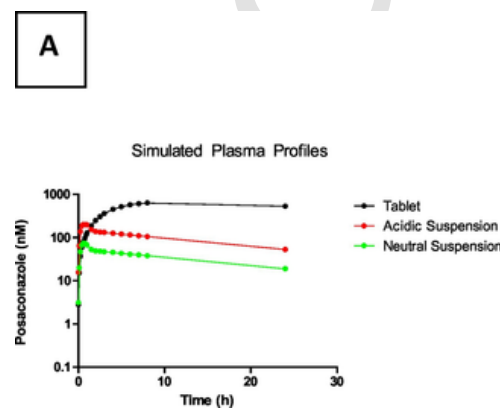
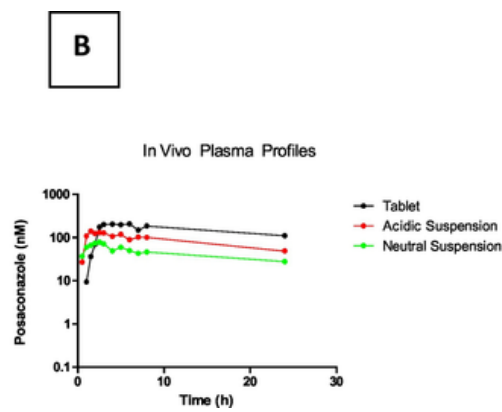
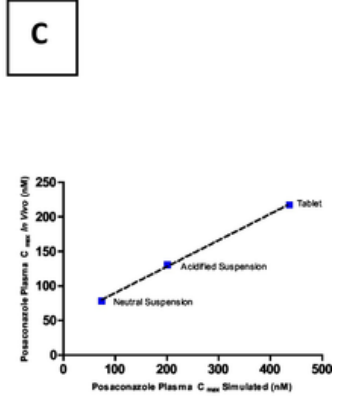

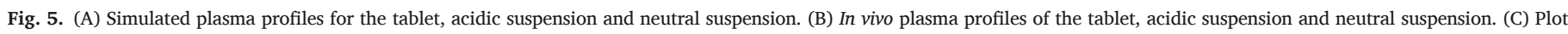
of the observed in vivo plasma $\mathrm{C}_{\max }$ values as a function of the predicted plasma $\mathrm{C}_{\max }$ values for the three different formulations. 
(IVIVC) level $\mathrm{A}$, the in vitro dissolution and in vivo input curves may be directly superimposable or may be made to be superimposable by the use of a scaling factor (Buchwald, 2003; Food and Drug Administration, 1997; González-García et al., 2015; Kesisoglou et al., 2015; Veng-Pedersen et al., 2000). However, it should be noted that scaling did not affect the outcoming ranking of formulation performance. Comparing Fig. 5A and B, the same ranking order in systemic outcome was established between predicted and observed plasma profiles. Plotting the plasma $\mathrm{C}_{\max }$ values of the in vivo versus the plasma $\mathrm{C}_{\max }$ values obtained from the simulation, a linear trend was observed (Fig. 5C).

\subsection{Visualization of the morphology and time to the appearance of posaconazole's precipitation}

When comparing human precipitation data for different weak bases such as posaconazole, dipyridamole and ketoconazole, it is clear that, apart from the physiological variables of the gastrointestinal tract (e.g., motility, transfer, dilutions, and intestinal uptake), the physicochemical properties of the compound will have a major impact on the precipitation kinetics of the drug upon entry in the small intestine. The maximum precipitated fraction of posaconazole was $92 \%$, tremendously higher than that observed for dipyridamole and ketoconazole ( $7 \%$ and $16 \%$, respectively) (Psachoulias et al., 2011). Therefore, microscopy and DSC studies were conducted in parallel to evaluate the morphology and time to appearance of posaconazole's precipitation. The formation of solid posaconazole was evaluated for the solution, acidic suspension and neutral suspension as a function of time (Fig. 6).
Regarding the $20 \mathrm{mg}$ solution, no precipitation was observed directly after the transfer of the acidic solution into the well, containing $200 \mathrm{mM}$ phosphate buffer (pH7.5). After $15 \mathrm{~min}$, small (ranging from 1 to $2 \mu \mathrm{m}$ to $50 \mu \mathrm{m}$ ) nuclei appeared (red arrows). A crystalline phase is created as a consequence of molecular aggregation processes in solution that lead to the formation of nuclei (with a configuration compatible with the crystal structure), which achieve a certain size for a sufficient time to enable growth into macroscopic crystals (Rodríguez-Hornedo and Murphy, 1999). From a mechanistic point of view, the precipitation process of a drug coming from a supersaturated solution consists of two phases: the first phase is the formation of nuclei (i.e., nucleation) and the second phase is the growing of macroscopic crystals (i.e., crystal growth) (Lindfors et al., 2008; Raina et al., 2015; Vekilov, 2010). On its turn, crystal growth consists of two steps: diffusion of molecules from the supersaturated solution to the crystal interface and integration of the molecule into the crystal lattice (Lindfors et al., 2008). At $30 \mathrm{~min}$, growing crystals (green arrows) were clearly observed that kept on growing until the last picture was taken at $24 \mathrm{~h}$ (blue arrows). As for the acidic suspension, initial solid particles were observed after transfer in the well under the microscope, as there are still 30\% undissolved particles present in this suspension. These particles can easily facilitate the process of precipitation as the required activation energy to form nuclei will be otiose. The appearance of crystal growth was highly pronounced after $30 \mathrm{~min}$ (purple arrow) and $24 \mathrm{~h}$ (orange arrow). Regarding the neutral suspension, neither the formation of nuclei nor the growth of crystals was observed, due to the absence of a 'spring' that could lead to eventual precipitation of the drug (Guzmán et al., 2004). Therefore, this experimental condition can be

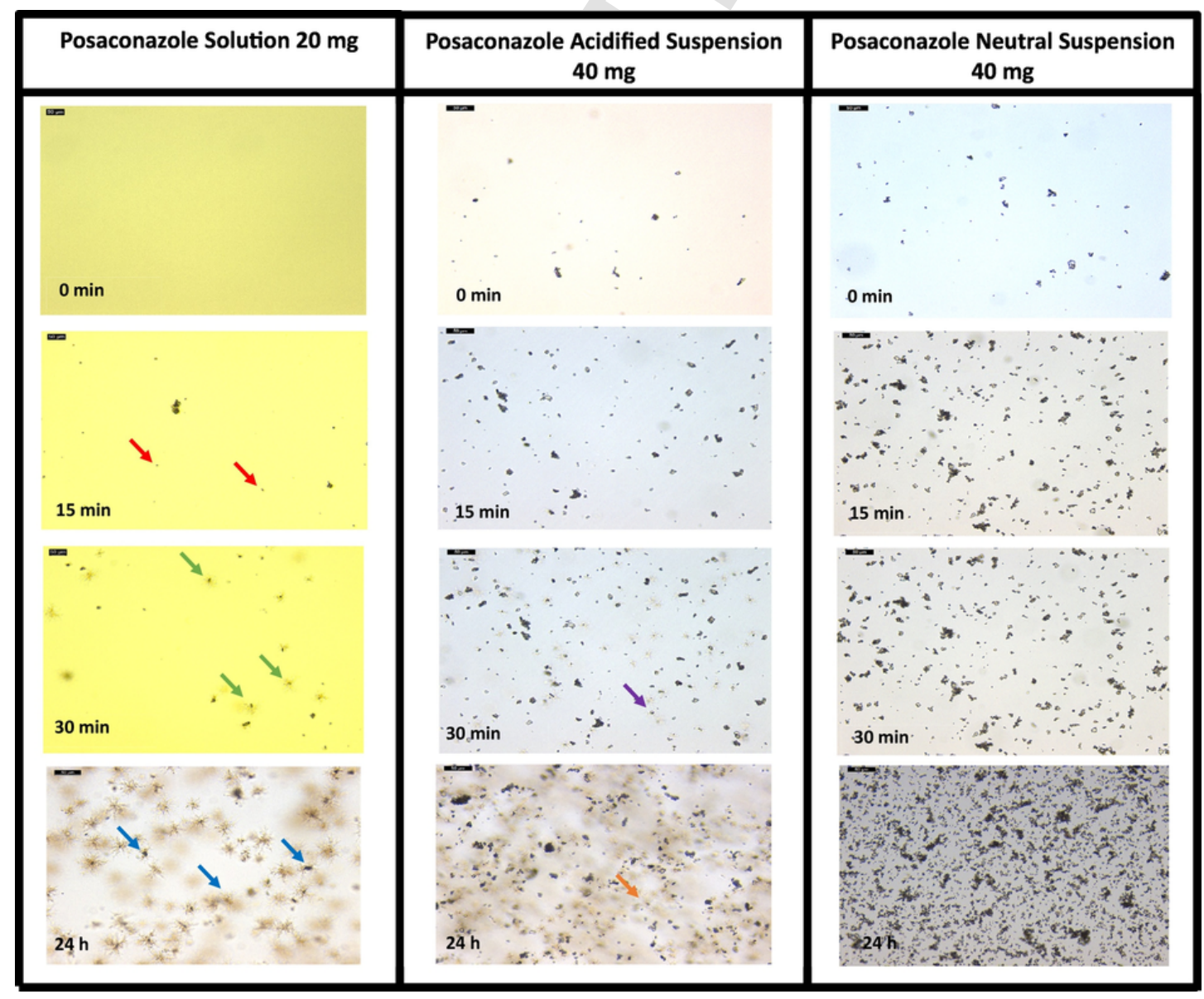

Fig. 6. Morphology and appearance of posaconazole suspended particles and formed precipitate as a function of time up to $24 \mathrm{~h}$. 
seen as a kind of control where the highlighted particles are representing the dispersed particles that were present in the neutral suspension from the beginning.
The precipitation-inhibiting effects of HPMC-AS on supersaturated concentrations were investigated by adding $0.05 \%(\mathrm{w} / \mathrm{v})$ of the polymer to $200 \mathrm{mM}$ of phosphate buffer (pH7.5) (Bevernage et al., 2011).

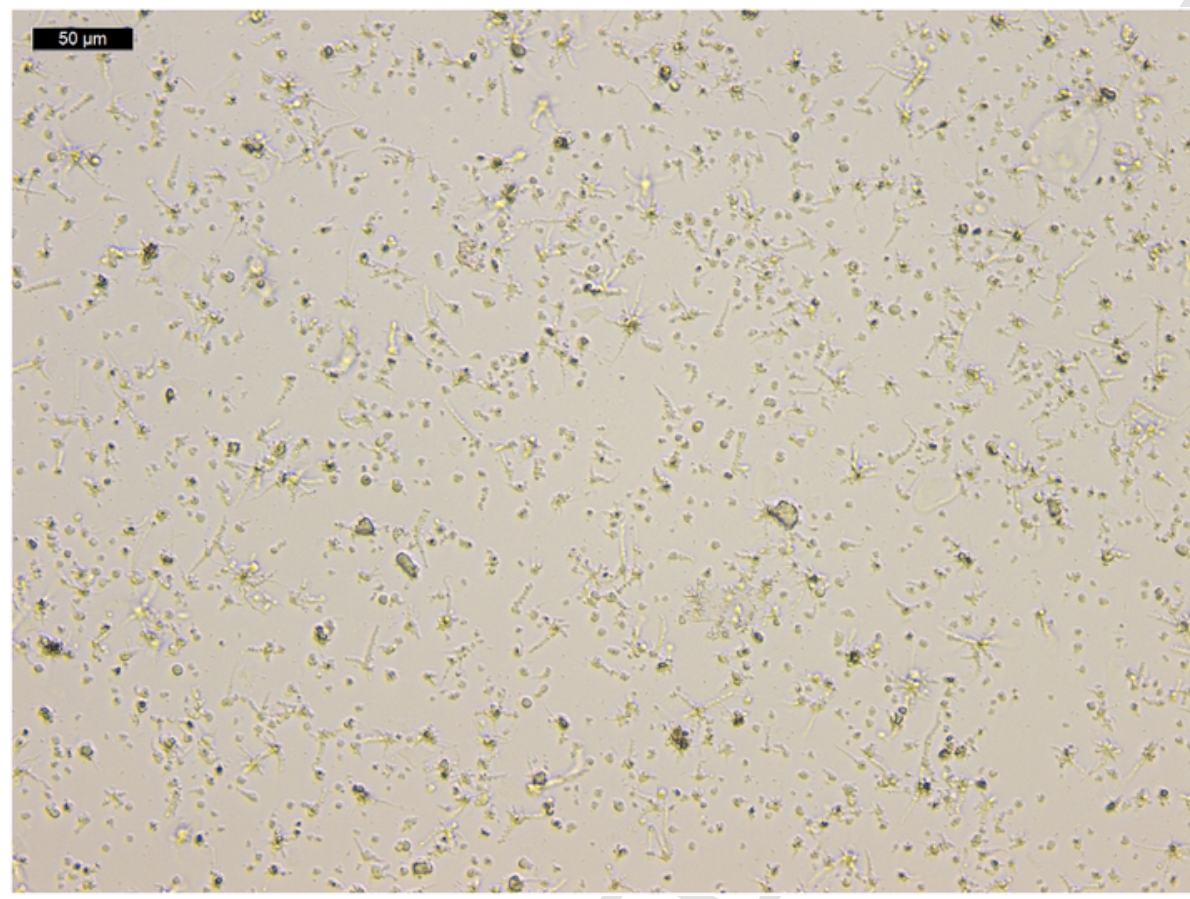

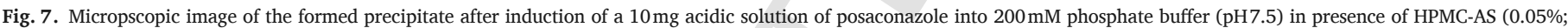
$\mathrm{w} / \mathrm{v})$.
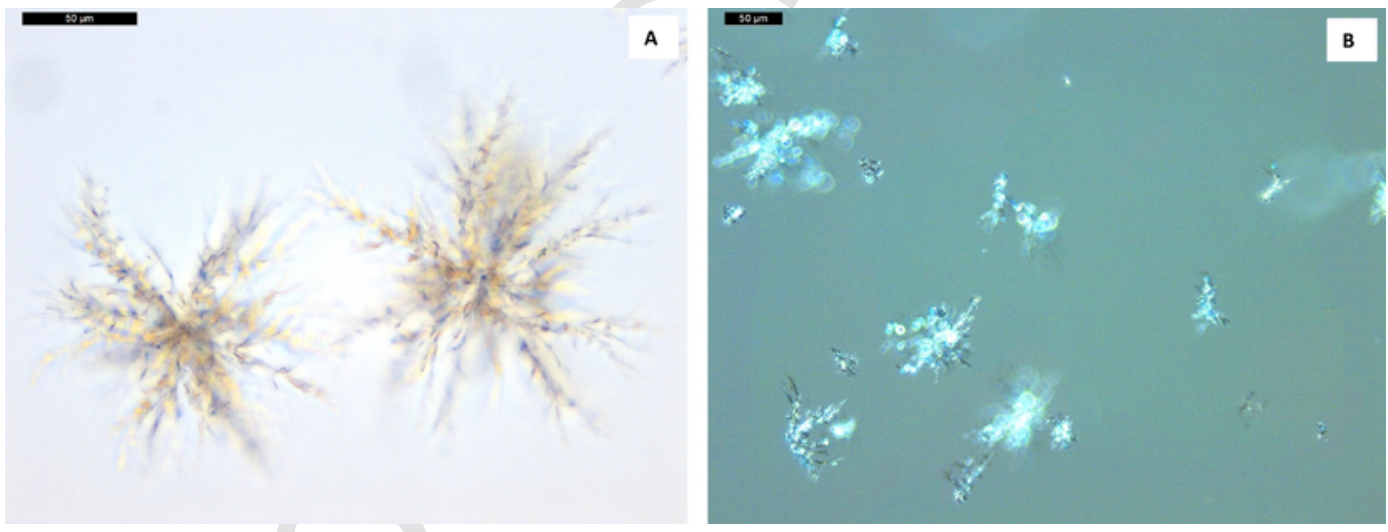

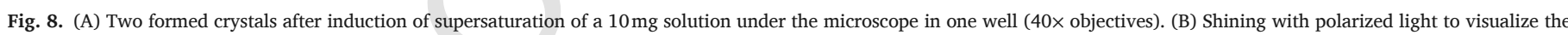
crystal lattice of the formed clusters ( $20 \times$ objectives).
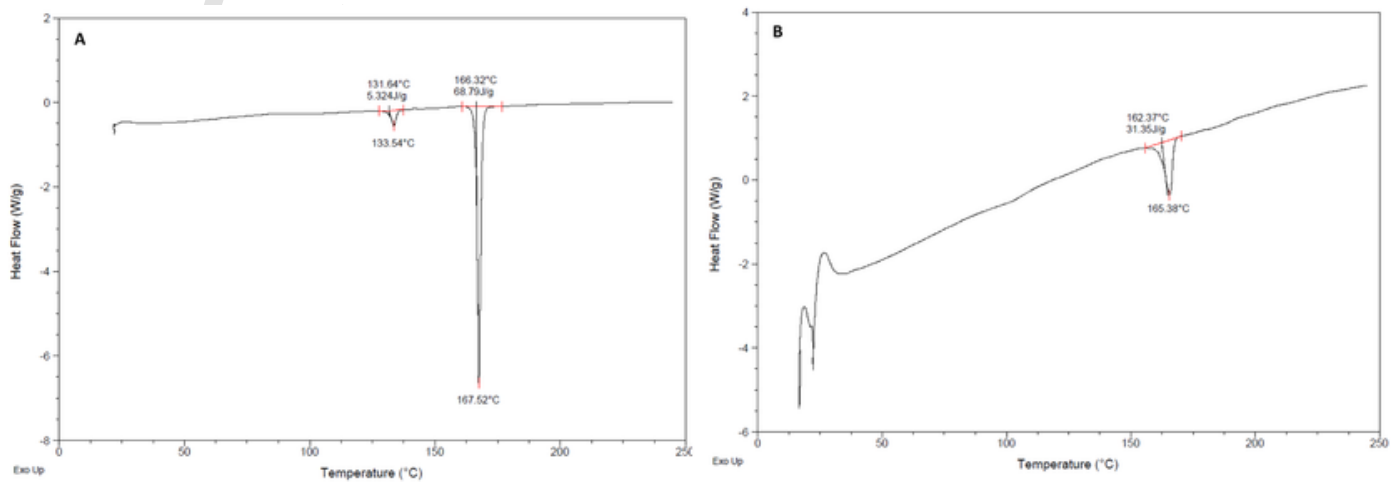

Fig. 9. DSC thermogram of (A) pure posaconazole and (B) precipitated posaconazole after $\mathrm{pH}$-shift induction for a $250 \mathrm{mg}$ solution from $\mathrm{pH} 1$ to $\mathrm{pH} 7.8$. 
After a 1:1 dilution with a $10 \mathrm{mg}$ solution of posaconazole ( $\mathrm{pH} 1.6)$, the time to induction of precipitation was checked and compared to the same conditions but without HPMC-AS. It was clearly seen that the induction of nuclei was delayed with $40 \mathrm{~min}$ compared to the condition where no HPMC-AS was added to the medium. Besides the delay in precipitation induction, there were also differences in morphology of the formed precipitate after $24 \mathrm{~h}$ (Fig. 7).

Several mechanisms have been put forward to describe the precipitation-inhibiting effects of excipients on the metastable state of supersaturation. For instance, it is hypothesized that HPMC-AS may increase the cluster-liquid interfacial energy resulting in a decrease of nuclei formation. Differences in morphology of formed precipitate in presence and absence of HPMC-AS can be explained by different nucleation mechanisms which may have a major impact on the formed solid-state of the precipitate (Hsieh et al., 2012). Lindfors et al. looked at the nucleation and crystal growth in supersaturated solutions of bicalutamide, in presence and absence of polyvinylpyrrolidone (PVP) (Lindfors et al., 2008). The polymer was adsorbed to the crystals that were formed in the solution, reducing the rate of crystal growth tremendously, explained by the classical nucleation and growth theory (Lindfors et al., 2008; Vekilov, 2010). It should be pointed out that in vitro conditions to study precipitation kinetics are controlled and can be performed in a 'clean, homogeneous' environment, not dealing with unintentionally or intentionally added surfaces or interfaces which may promote nucleation (Rodríguez-Hornedo and Murphy, 1999). The human GI tract is, however, a heterogeneous environment that can trigger the onset of precipitation and influence the nucleation process tremendously due to the presence of endogenous components and its complex design.

\subsection{Characterization of the solid-state characteristics of the formed precipitate by POM and DSC}

Techniques that can be applied to investigate the solid state of drugs in human/simulated fluids include, for example, X-ray powder diffraction (XRPD), solid-state nuclear magnetic resonance (NMR), synchrotron small-angle X-ray scattering (SAXS), DSC and polarized optical microscopy (POM) (Hsieh et al., 2012; Psachoulias et al., 2011; Raina et al., 2015; Rodríguez-Spong et al., 2008). Psachoulias et al. demonstrated the presence of amorphous ketoconazole in human aspirates of the duodenum by performing XRPD analysis (Psachoulias et al., 2011). In order to gain more insights into the solid-state characteristics of posaconazole after formation of crystal growth, POM and DSC were conducted. Fig. $8 \mathrm{~A}$ zooms in on two formed crystals ( $40 \times$ Nomarski objectives) and Fig. $8 \mathrm{~B}$ looks at the crystallinity by shining with polarized light on the crystal lattice.

In a next step, precipitated posaconazole was isolated after inducing a pH-shift for a $250 \mathrm{mg}$ posaconazole solution from $\mathrm{pH} 1$ to $\mathrm{pH} 7.8$ ( $\mathrm{NaOH}$ titration). In that case, a sufficient amount of precipitated posaconazole was obtained and analyzed by DSC for looking at the solid-state characteristics. As a reference and control, a DSC analysis was performed for the posaconazole powder as such (Fig. 9).

Remarkably, two different endothermic events were occurring around $405.5 \mathrm{~K}\left(132^{\circ} \mathrm{C}\right)$ and $440.5 \mathrm{~K}\left(167^{\circ} \mathrm{C}\right)$, whereas the melting point $\left(\mathrm{T}_{\mathrm{m}}\right)$ of posaconazole was determined to be $443 \mathrm{~K}\left(170.1 \pm 0.5^{\circ} \mathrm{C}\right)$ (Fig. 9A). The appearance of the first peak is related to a nematic-like phase transition, whereas the latter one is related with the $\mathrm{T}_{\mathrm{m}}$, as described by Adrjanowicz et al. (Adrjanowicz et al., 2013). Fig. 9B shows the thermogram of the precipitated posaconazole, which appears to be a single peak that takes up the energy of heating in order to break the crystal lattice at a temperature of $438.5 \mathrm{~K}\left(165.38^{\circ} \mathrm{C}\right)$. The physical and biopharmaceutical properties of polymorphs, like melting point and equilibrium solubility for instance, may be widely different.
To the extent of our knowledge, there are six polymorphs described of posaconazole (Zografos et al., 2015). There was a minor difference observed between the endotherm event of the precipitate $(438.5 \mathrm{~K})$ and the $\mathrm{T}_{\mathrm{m}}$ of posaconazole $(443 \mathrm{~K})$. Due to the fact that there is a lack of information regarding the physicochemical/biopharmaceutical properties of the different polymorphs, we are not able to say anything clear about which polymorph was present in the precipitate. However, since polarized optical microscopy (Fig. 7B) clearly showed birefringent particles and since the DSC analysis pointed out a defined endothermic event, it is safe to mention that the precipitate was crystalline. Hsieh et al. observed the precipitation behavior of 10 different weak bases: when an amorphous precipitate was formed, a prolonged duration of supersaturation was observed; for the compounds that precipitated to crystalline forms, the observed supersaturation time window was short, as also observed for posaconazole (Hsieh et al., 2012).

\subsection{Conclusion \& future directives}

This manuscript demonstrated the predictive power of the GIS in order to capture the intraluminal behavior of four different SDDS of posaconazole. To evaluate the formulation performance in terms of oral bioavailability, the GIS experiments were coupled with an in silico PK model that simulated the plasma profiles. The same ranking in formulation performance was predicted as compared with the in vivo situation. Because precipitation was extensively pronounced, additional microscopy and DSC experiments were performed to elucidate the precipitation kinetics and the solid-state morphology. This work successfully demonstrated an in vitro/in silico/in vivo for screening different oral drug products containing the same drug compound. The microscopy studies demonstrated the interesting potential to look at precipitation kinetics in presence or absence of a precipitation-inhibitor. This promising strategy can be applied for more compounds and precipitation-inhibitors in future studies. Another follow-up study that will be put forward is to evaluate higher doses of posaconazole (therapeutic dose regimen is $400 \mathrm{mg}$ per day of oral suspension) that can give us more information about liquid-liquid phase separation (LLPS) of posaconazole, a potential scenario that could occur in vivo as well when dealing with highly supersaturated solutions (Indulkar et al., 2015). We hope that this research will be of interest for formulation scientists in R\&D companies (including generic drug companies) who may use this work as a rational framework and scientific basis for screening different oral drug products of the same drug compound in order to gain comprehensive information about the in vivo performance of the formulation prior to the start of the clinical trials.

\section{Acknowledgments}

This work was supported by grant \# HHSF223201510157C and grant \# HHSF223201310144C by the U.S. Food and Drug Administration (FDA). Bart Hens would like to acknowledge the Internal Funds of KU Leuven (PDM/17/164). This report represents the scientific views of the authors and not necessarily that of the FDA. Authors have no conflicts of interest to declare.

\section{Appendix A. Supplementary data}

Supplementary data to this article can be found online at https:// doi.org/10.1016/j.ejps.2018.01.039.

\section{References}

Adrjanowicz, K., Kaminski, K., Wlodarczyk, P., Grzybowska, K., Tarnacka, M., Zakowiecki, D., Garbacz, G., Paluch, M., Jurga, S., 2013. Molecular dynamics of the supercooled pharmaceutical agent posaconazole studied via differential scanning 
calorimetry and dielectric and mechanical spectroscopies. Mol. Pharm. 10, 3934-3945. https://doi.org/10.1021/mp4003915.

Augustijns, P., Brewster, M.E., 2012. Supersaturating drug delivery systems: fast is not necessarily good enough. J. Pharm. Sci. 101, 7-9. https://doi.org/10.1002/jps.22750.

Augustijns, P., Wuyts, B., Hens, B., Annaert, P., Butler, J., Brouwers, J., 2014. A review of drug solubility in human intestinal fluids: implications for the prediction of oral absorption. Eur. J. Pharm. Sci. 57, 322-332. https://doi.org/10.1016/j.ejps.2013.08. 027.

Bevernage, J., Forier, T., Brouwers, J., Tack, J., Annaert, P., Augustijns, P., 2011. Excipient-mediated supersaturation stabilization in human intestinal fluids. Mol. Pharm. 8, 564-570. https://doi.org/10.1021/mp100377m.

Bevernage, J., Brouwers, J., Annaert, P., Augustijns, P., 2012. Drug precipitation-permeation interplay: supersaturation in an absorptive environment. Eur. J. Pharm. Biopharm. 82, 424-428. https://doi.org/10.1016/j.ejpb.2012.07.009.

Bevernage, J., Brouwers, J., Brewster, M.E., Augustijns, P., 2013. Evaluation of gastrointestinal drug supersaturation and precipitation: strategies and issues. Int. J. Pharm. 453, 25-35. https://doi.org/10.1016/j.ijpharm.2012.11.026.

Brewster, M.E., Vandecruys, R., Verreck, G., Peeters, J., 2008. Supersaturating drug delivery systems: effect of hydrophilic cyclodextrins and other excipients on the formation and stabilization of supersaturated drug solutions. Pharmazie 63, 217-220.

Brouwers, J., Brewster, M.E., Augustijns, P., 2009. Supersaturating drug delivery systems: the answer to solubility-limited oral bioavailability?. J. Pharm. Sci. 98, 2549-2572. https://doi.org/10.1002/jps.21650.

Brouwers, J., Geboers, S., Mols, R., Tack, J., Augustijns, P., 2017. Gastrointestinal behavior of itraconazole in humans - part 1: supersaturation from a solid dispersion and a cyclodextrin-based solution. Int. J. Pharm. 525, 211-217. https://doi.org/10.1016/j. ijpharm.2017.04.029.

Buchwald, P., 2003. Direct, differential-equation-based in-vitro-in-vivo correlation (IVIVC) method. J. Pharm. Pharmacol. 55, 495-504. https://doi.org/10.1211/002235702847.

Carlert, S., Pålsson, A., Hanisch, G., von Corswant, C., Nilsson, C., Lindfors, L., Lennernäs, H., Abrahamsson, B., 2010. Predicting intestinal precipitation-a case example for a basic BCS class II drug. Pharm. Res. 27, 2119-2130. https://doi.org/10.1007/ s11095-010-0213-8.

Carlert, S., Akesson, P., Jerndal, G., Lindfors, L., Lennernäs, H., Abrahamsson, B., 2012. In vivo dog intestinal precipitation of mebendazole: a basic BCS class II drug. Mol. Pharm. 9, 2903-2911. https://doi.org/10.1021/mp300224h.

Fong, S.Y.K., Bauer-Brandl, A., Brandl, M., 2016. Oral bioavailability enhancement through supersaturation: an update and meta-analysis. Expert Opin Drug Deliv 1-24. https://doi.org/10.1080/17425247.2016.1218465.

Food \& Drug Administration, 1997. Guidance for Industry Extended Release Oral Dosage Forms: Development, Evaluation, and Application of In Vitro/In Vivo Correlations.

Food \& Drug Administration, 2001. Guidance for Industry: Bioanalytical Method Validation.

Gao, P., Shi, Y., 2012. Characterization of supersaturatable formulations for improved absorption of poorly soluble drugs. AAPS J. 14, 703-713. https://doi.org/10.1208/ s12248-012-9389-7.

González-García, I., Mangas-Sanjuán, V., Merino-Sanjuán, M., Bermejo, M., 2015. In vitro-in vivo correlations: general concepts, methodologies and regulatory applications. Drug Dev. Ind. Pharm. 41, 1935-1947. https://doi.org/10.3109/03639045. 2015.1054833.

Guzmán, H., Tawa, M., Zhang, Z., Ratanabanangkoon, P., Shaw, P., Mustonen, P., Gardner, C., Chen, H., Moreau, J., Almarsson, O., Remenar, J., 2004. A 'Spring and Parachute' Approach to Designing Solid Celecoxib Formulations Having Enhanced Oral Absorption, (Presented at the AAPS)

Hasler, W.L., 2008. The physiology of gastric motility and gastric emptying. In: Adjunctessor, T.Y.M.P. (Ed.), Textbook of Gastroenterology. Blackwell Publishing Ltd., pp. 207-230. https://doi.org/10.1002/9781444303254.ch10.

Hens, B., Brouwers, J., Anneveld, B., Corsetti, M., Symillides, M., Vertzoni, M., Reppas, C., Turner, D.B., Augustijns, P., 2014. Gastrointestinal transfer: in vivo evaluation and implementation in in vitro and in silico predictive tools. Eur. J. Pharm. Sci. 63, 233-242. https://doi.org/10.1016/j.ejps.2014.07.008.

Hens, B., Brouwers, J., Corsetti, M., Augustijns, P., 2016. Supersaturation and precipitation of posaconazole upon entry in the upper small intestine in humans. J. Pharm. Sci. 105, 2677-2684. https://doi.org/10.1002/jps.24690.

Hens, B., Corsetti, M., Brouwers, J., Augustijns, P., 2016. Gastrointestinal and systemic monitoring of Posaconazole in humans after fasted and fed state Administration of a Solid Dispersion. J. Pharm. Sci. 105, 2904-2912. https://doi.org/10.1016/j.xphs. 2016.03.027

Hens, B., Corsetti, M., Spiller, R., Marciani, L., Vanuytsel, T., Tack, J., Talattof, A., Amidon, G.L., Koziolek, M., Weitschies, W., Wilson, C.G., Bennink, R.J., Brouwers, J., Augustijns, P., 2016. Exploring gastrointestinal variables affecting drug and formulation behavior: methodologies, challenges and opportunities. Int. J. Pharm. 59, 79-97. https://doi.org/10.1016/j.ijpharm.2016.11.063.

Hens, B., Pathak, S.M., Mitra, A., Patel, N., Liu, B., Patel, S., Jamei, M., Brouwers, J., Augustijns, P., Turner, D.B., 2017. In silico modeling approach for the evaluation of gastrointestinal dissolution, supersaturation, and precipitation of posaconazole. Mol. Pharm. 14, 4321-4333. https://doi.org/10.1021/acs.molpharmaceut.7b00396.

Hens, B., Tsume, Y., Bermejo, M., Paixao, P., Koenigsknecht, M.J., Baker, J.R., Hasler, W.L., Lionberger, R., Fan, J., Dickens, J., Shedden, K., Wen, B., Wysocki, J., Loebenberg, R., Lee, A., Frances, A., Amidon, G., Yu, A., Benninghoff, G., Salehi, N., Talattof, A., Sun, D., Amidon, G.L., 2017. Low buffer capacity and alternating motility along the human gastrointestinal tract: implications for in vivo dissolution and absorption of Ionizable drugs. Mol. Pharm. 14, 4281-4294. https://doi.org/10.1021/acs. molpharmaceut.7b00426.

Hsieh, Y.-L., Ilevbare, G.A., Van Eerdenbrugh, B., Box, K.J., Sanchez-Felix, M.V., Taylor, L.S., 2012. pH-Induced precipitation behavior of weakly basic compounds: determination of extent and duration of supersaturation using potentiometric titration and correlation to solid state properties. Pharm. Res. 29, 2738-2753. https://doi.org/10. 1007/s11095-012-0759-8.

Indulkar, A.S., Box, K.J., Taylor, R., Ruiz, R., Taylor, L.S., 2015. pH-dependent liquid-liquid phase separation of highly supersaturated solutions of weakly basic drugs. Mol. Pharm. 12, 2365-2377. https://doi.org/10.1021/acs.molpharmaceut.5b00056.

Jackson, M.J., Toth, S.J., Kestur, U.S., Huang, J., Qian, F., Hussain, M.A., Simpson, G.J., Taylor, L.S., 2014. Impact of polymers on the precipitation behavior of highly supersaturated aqueous danazol solutions. Mol. Pharm. 11, 3027-3038. https://doi.org/10. 1021/mp500201s.

Kersemaekers, W.M., van Iersel, T., Nassander, U., O'Mara, E., Waskin, H., Caceres, M., van Iersel, M.L.P.S., 2015. Pharmacokinetics and safety study of posaconazole intravenous solution administered peripherally to healthy subjects. Antimicrob. Agents Chemother. 59, 1246-1251. https://doi.org/10.1128/AAC.04223-14.

Kesisoglou, F., Xia, B., Agrawal, N.G.B., 2015. Comparison of deconvolution-based and absorption modeling IVIVC for extended release formulations of a BCS III drug development candidate. AAPS J. 17, 1492-1500. https://doi.org/10.1208/ s12248-015-9816-7.

Kostewicz, E.S., Wunderlich, M., Brauns, U., Becker, R., Bock, T., Dressman, J.B., 2004 Predicting the precipitation of poorly soluble weak bases upon entry in the small in testine. J. Pharm. Pharmacol. 56, 43-51. https://doi.org/10.1211/0022357022511.

Kostewicz, E.S., Aarons, L., Bergstrand, M., Bolger, M.B., Galetin, A., Hatley, O., Jamei, M., Lloyd, R., Pepin, X., Rostami-Hodjegan, A., Sjögren, E., Tannergren, C., Turner, D.B., Wagner, C., Weitschies, W., Dressman, J., 2014. PBPK models for the prediction of in vivo performance of oral dosage forms. Eur. J. Pharm. Sci. 57, 300-321. https://doi. org/10.1016/j.ejps.2013.09.008

Kostewicz, E.S., Abrahamsson, B., Brewster, M., Brouwers, J., Butler, J., Carlert, S., Dickinson, P.A., Dressman, J., Holm, R., Klein, S., Mann, J., McAllister, M., Minekus, M., Muenster, U., Müllertz, A., Verwei, M., Vertzoni, M., Weitschies, W., Augustijns, P., 2014. In vitro models for the prediction of in vivo performance of oral dosage forms. Eur. J. Pharm. Sci. 57, 342-366. https://doi.org/10.1016/j.ejps.2013.08.024.

Kourentas, A., Vertzoni, M., Symillides, M., Hens, B., Brouwers, J., Augustijns, P., Reppas, C., 2016. In vitro evaluation of the impact of gastrointestinal transfer on luminal performance of commercially available products of posaconazole and itraconazole using BioGIT. Int. J. Pharm. 515, 352-358. https://doi.org/10.1016/j.ijpharm.2016.10.018.

Laitinen, R., Löbmann, K., Grohganz, H., Priemel, P., Strachan, C.J., Rades, T., 2017. Supersaturating drug delivery systems: the potential of co-amorphous drug formulations. Int. J. Pharm. 532, 1-12. https://doi.org/10.1016/j.ijpharm.2017.08.123.

Lindfors, L., Forssén, S., Westergren, J., Olsson, U., 2008. Nucleation and crystal growth in supersaturated solutions of a model drug. J. Colloid Interface Sci. 325, 404-413. https://doi.org/10.1016/j.jcis.2008.05.034

Lipert, M., Rodríguez-Hornedo, N., 2015. Cocrystal transition points: role of cocrystal solubility, drug solubility, and solubilizing agents. Mol. Pharm. 12, 3535-3546. https:// doi.org/10.1021/acs.molpharmaceut.5b00111.

Loftsson, T., Brewster, M.E., 2010. Pharmaceutical applications of cyclodextrins: basic science and product development. J. Pharm. Pharmacol. 62, 1607-1621. https://doi. org/10.1111/j.2042-7158.2010.01030.x.

Lu, E., Li, S., Wang, Z., 2017. Biorelevant test for supersaturable formulation. Asian J. Pharm. Sci. 12, 9-20. https://doi.org/10.1016/j.ajps.2016.10.002.

Matsui, K., Tsume, Y., Amidon, G.E., Amidon, G.L., 2015. In vitro dissolution of fluconazole and dipyridamole in gastrointestinal simulator (GIS), predicting in vivo dissolution and drug-drug interaction caused by acid-reducing agents. Mol. Pharm. 12, 2418-2428. https://doi.org/10.1021/acs.molpharmaceut.5b00135.

Matsui, K., Tsume, Y., Amidon, G.E., Amidon, G.L., 2016. The evaluation of in vitro drug dissolution of commercially available oral dosage forms for Itraconazole in gastrointestinal simulator with biorelevant media. J. Pharm. Sci. 105, 2804-2814. https://doi. org/10.1016/j.xphs.2016.02.020.

Matsui, K., Tsume, Y., Takeuchi, S., Searls, A., Amidon, G.L., 2017. Utilization of gastrointestinal simulator, an in vivo predictive dissolution methodology, coupled with computational approach to forecast oral absorption of dipyridamole. Mol. Pharm. 14, 1181-1189. https://doi.org/10.1021/acs.molpharmaceut.6b01063.

Mudie, D.M., Murray, K., Hoad, C.L., Pritchard, S.E., Garnett, M.C., Amidon, G.L., Gowland, P.A., Spiller, R.C., Amidon, G.E., Marciani, L., 2014. Quantification of gastrointestinal liquid volumes and distribution following a $240 \mathrm{~mL}$ dose of water in the fasted state. Mol. Pharm. 11, 3039-3047. https://doi.org/10.1021/mp500210c.

Murray, K., Hoad, C.L., Mudie, D.M., Wright, J., Heissam, K., Abrehart, N., Pritchard, S.E., Al Atwah, S., Gowland, P.A., Garnett, M.C., Amidon, G.E., Spiller, R.C., Amidon, G.L. Marciani, L., 2017. Magnetic resonance imaging quantification of fasted state colonic liquid pockets in healthy humans. Mol. Pharm. 14, 2629-2638. https://doi.org/10. 1021/acs.molpharmaceut.7b00095.

Patel, D.D., Anderson, B.D., 2014. Effect of precipitation inhibitors on indomethacin supersaturation maintenance: mechanisms and modeling. Mol. Pharm. 11, 1489-1499. https://doi.org/10.1021/mp400658k.

Peppas, N.A., 1985. Analysis of Fickian and non-Fickian drug release from polymers. Pharm. Acta Helv. 60, 110-111.

Polster, C.S., Atassi, F., Wu, S.-J., Sperry, D.C., 2010. Use of artificial stomach-duodenum model for investigation of dosing fluid effect on clinical trial variability. Mol. Pharm. 7, 1533-1538. https://doi.org/10.1021/mp100116g. 
Psachoulias, D., Vertzoni, M., Goumas, K., Kalioras, V., Beato, S., Butler, J., Reppas, C., 2011. Precipitation in and supersaturation of contents of the upper small intestine after administration of two weak bases to fasted adults. Pharm. Res. 28, 3145-3158. https://doi.org/10.1007/s11095-011-0506-6.

Raina, S.A., Van Eerdenbrugh, B., Alonzo, D.E., Mo, H., Zhang, G.G.Z., Gao, Y., Taylor, L.S., 2015. Trends in the precipitation and crystallization behavior of supersaturated aqueous solutions of poorly water-soluble drugs assessed using synchrotron radiation. J. Pharm. Sci. 104, 1981-1992. https://doi.org/10.1002/jps.24423.

Rodríguez-Hornedo, N., Murphy, D., 1999. Significance of controlling crystallization mechanisms and kinetics in pharmaceutical systems. J. Pharm. Sci. 88, 651-660. https://doi.org/10.1021/js980490h.

Rodríguez-Spong, B., Acciacca, A., Fleisher, D., Rodríguez-Hornedo, N., 2008. PH-induced nanosegregation of ritonavir to lyotropic liquid crystal of higher solubility than crystalline polymorphs. Mol. Pharm. 5, 956-967. https://doi.org/10.1021/mp800114k.

Rubbens, J., Brouwers, J., Tack, J., Augustijns, P., 2016. Gastrointestinal dissolution, supersaturation and precipitation of the weak base indinavir in healthy volunteers. Eur. J. Pharm. Biopharm. 109, 122-129. https://doi.org/10.1016/j.ejpb.2016.09.014.

Sansone-Parsons, A., Krishna, G., Calzetta, A., Wexler, D., Kantesaria, B., Rosenberg, M.A., Saltzman, M.A., 2006. Effect of a nutritional supplement on posaconazole pharmacokinetics following oral administration to healthy volunteers. Antimicrob. Agents Chemother. 50, 1881-1883. https://doi.org/10.1128/AAC.50.5.1881-1883.2006.

Shi, Y., Erickson, B., Jayasankar, A., Lu, L., Marsh, K., Menon, R., Gao, P., 2016. Assessing supersaturation and its impact on in vivo bioavailability of a low-solubility compound ABT-072 with a dual pH, two-phase dissolution method. J. Pharm. Sci. 105, 2886-2895. https://doi.org/10.1016/j.xphs.2016.04.036.

Stappaerts, J., Geboers, S., Snoeys, J., Brouwers, J., Tack, J., Annaert, P., Augustijns, P., 2015. Rapid conversion of the ester prodrug abiraterone acetate results in intestinal supersaturation and enhanced absorption of abiraterone: in vitro, rat in situ and human in vivo studies. Eur. J. Pharm. Biopharm. 90, 1-7. https://doi.org/10.1016/j. ejpb.2015.01.001.

Sun, D.D., Lee, P.I., 2013. Evolution of supersaturation of amorphous pharmaceuticals: the effect of rate of supersaturation generation. Mol. Pharm. 10, 4330-4346. https://doi. org/10.1021/mp400439q.
Sun, D.D., Wen, H., Taylor, L.S., 2016. Non-sink dissolution conditions for predicting product quality and in vivo performance of supersaturating drug delivery systems. J. Pharm. Sci. 105, 2477-2488. https://doi.org/10.1016/j.xphs.2016.03.024.

Tsume, Y., Mudie, D.M., Langguth, P., Amidon, G.E., Amidon, G.L., 2014. The biopharmaceutics classification system: subclasses for in vivo predictive dissolution (IPD) methodology and IVIVC. Eur. J. Pharm. Sci. 57, 152-163. https://doi.org/10.1016/j. ejps.2014.01.009.

Tsume, Y., Igawa, N., Drelich, A.J., Amidon, G.E., Amidon, G.L., 2017. The combination of GIS and biphasic to better predict in vivo dissolution of BCS class IIb drugs, ketoconazole and raloxifene. J. Pharm. Sci.https://doi.org/10.1016/j.xphs.2017.09.002.

Tsume, Y., Matsui, K., Searls, A.L., Takeuchi, S., Amidon, G.E., Sun, D., Amidon, G.L., 2017. The impact of supersaturation level for oral absorption of BCS class IIb drugs, dipyridamole and ketoconazole, using in vivo predictive dissolution system: gastrointestinal simulator (GIS). Eur. J. Pharm. Sci. 102, 126-139. https://doi.org/10.1016/j. ejps.2017.02.042.

Vekilov, P.G., 2010. The two-step mechanism of nucleation of crystals in solution. Nano 2, 2346-2357. https://doi.org/10.1039/c0nr00628a.

Veng-Pedersen, P., Gobburu, J.V., Meyer, M.C., Straughn, A.B., 2000. Carbamazepine level-A in vivo-in vitro correlation (IVIVC): a scaled convolution based predictive approach. Biopharm. Drug Dispos. 21, 1-6.

Verwei, M., Minekus, M., Zeijdner, E., Schilderink, R., Havenaar, R., 2016. Evaluation of two dynamic in vitro models simulating fasted and fed state conditions in the upper gastrointestinal tract (TIM-1 and tiny-TIM) for investigating the bioaccessibility of pharmaceutical compounds from oral dosage forms. Int. J. Pharm. 498, 178-186. https://doi.org/10.1016/j.ijpharm.2015.11.048.

Williams, H.D., Trevaskis, N.L., Charman, S.A., Shanker, R.M., Charman, W.N., Pouton, C.W., Porter, C.J.H., 2013. Strategies to address low drug solubility in discovery and development. Pharmacol. Rev. 65, 315-499.

Xu, S., Dai, W.-G., 2013. Drug precipitation inhibitors in supersaturable formulations. Int. J. of Pharm. 453, 36-43. https://doi.org/10.1016/j.ijpharm.2013.05.013.

Zografos, S., Fertaki, S., Kontoyannis, C., 2015. Identification and Quantitative Analysis of Posaconazole API in Noxafil@ Oral Suspension. Presented at the 10o ПANEA HHNIO

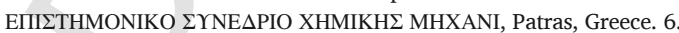

